Just one more point I have in mind here, and that is really an entomological problem and some day at the entomologists' meetings when interest lags, we might start the discussion. It is very doubtful that nicotine functions entirely in its volatile condition. It is more likely a true contact posion and does not function as a gas. That is all I want to say now; I don't want to start anything at this time.

Mr. N. J. Giddings: It was suggested by Dr. Lyman, before I gave my paper, that a word as to the activity and interest in regard to this project might not be out of place. Last year the Advisory Board of American Plant Pathologists asked me to act as leader in an endeavor to encourage cooperative work on the dusting project. In this connection a general outline or plan was sent to twenty-six states. Twentythree of those replied, indicating that the interest was great. Eighteen states were strongly favorable toward further work in connection with dusting, and at least nine states reported experimental work during the season. Seven of them have already turned in data to me. These statements relate particularly to the pathological side. I might add that the outline was not sent generally to the South because it was rather late in the season. This is merely an indication of the interest that the dusting problem has for the whole country.

President WiLmon Newell: We have undoubtedly gained a great deal of good out of these discussions.

Adjournment.

\title{
ARSENIC FOR GRUB-INFESTED SOILS
}

\section{By J. F. Illingworth, Gordonvale, near Cairns, North Queensland}

For some time we have been experimenting with poisons applied to the soil for the control of white grubs, since, as is well known, these pests are a serious menace to the growth of sugar-cane, particularly on the red volcanic soils in North Queensland.

Naturally our earlier experiments were in the laboratory, where the poisons were tried in small pots of soil. This was done by mixing the two together thoroughly before introducing living grubs, which by their natural process of ingesting quantities of soil inevitably absorbed some of the poison. Most satisfactory results were obtained with the ordinary crude white arsenic (arsenious acid).

By using a liberal sprinkling of the arsenic through the soil we found that the grubs all succumbed in from one to four days, and this same result was secured with each repetition of the experiment. 
We now have many experiments under way in cane areas that have been regularly devastated, but it will be some time before we can hope for conclusive results, i.e. as to the amount of arsenic required per acre, method of application, etc. Hence I was glad to avail myself of an opportunity to experiment upon troublesome grubs in the garden.

During July and August, cucumbers which had been planted in hills with cowdung, failed completely. They had hardly started to grow before the leaves began to yellow, and the vines became stunted in spite of the fact that they were given an abundance of water. When they were dug out the soil was found to be filled with white grubs; and there was every indication that they had destroyed the small feeding roots. This pest proved to be Isodon puncticollis Macleay, commonly known as the Gauger Beetle, because of its destructive habit of digging holes into potatoes and various root crops.

I at once tried the application of arsenic to these hills, using the poison at the rate of about 80 pounds per acre, to see if it would destroy the mature grubs, leaving two hills for checks. About a fortnight later I could only find two live grubs in the four treated hills, while one of the checks had 46 and the other 21 full-grown grubs.

This result was so encouraging that I prepared six new hills on September 27 th, and on October 1Sth, when the soil was full of newly-hatched grubs, I treated five of the hills with arsenic at the same rate, leaving one for a check. A week later, I could find no grubs in the treated hills, though two live beetles were uncovered. The check which was about six feet from the others, had 61 grubs.

An additional experiment was tried, in which the soil and dung were dusted with arsenic at the time that the hills were prepared; in this case, too, a single hill was kept for check. Three weeks later these hills were examined; six live beetles but no grubs were found in the treated hills, while numerous young grubs were in the check.

These results are most encouraging, especially since I have been able to demonstrate that the poison has no detrimental effect upon growing plants, even when used in excessive quantities, i.e. 200 pounds per acre. Furthermore I have found by careful chemical tests, prepared by the mill chemists, that sugar cane grown on land so treated takes up none of the poison-not a trace of it could be found in the juice. Growth on treated soils is most vigorous, so the only possible disadvantage may arise from the action of the arsenic upon soil bacteria, especially if we find it necessary to use the poison in large quantities. This, however, can only be demonstrated after extended application. 